\title{
“O SONHO DA RAZÃO”: O DIÁLOGO INTERARTES E A FORMAÇÃO DO LEITOR EM GÉMEOS, DE MÁRIO CLÁUDIO
}

Sheila Jacob ${ }^{1}$

RESUMO: Este artigo propõe uma leitura do romance Gémeos, do escritor português Mário Cláudio, a partir do diálogo que a obra literária estabelece com alguns quadros do pintor espanhol Goya. Veremos como, a partir da interação entre distintas formas de produção artística, o texto possibilita que se questionem os limites e as possibilidades da linguagem ficcional, explicitando os processos de criação e formando, assim, um leitor atento, que precisa sair de uma situação confortável para tornar-se produtor de conhecimento.

PALAVRAS-CHAVE: Gémeos, de Mário Cláudio; Goya; diálogo interartes; formação do leitor.

\section{“THE SLEEP OF REASON": THE DIALOGUE BETWEEN ARTS AND THE READER'S FORMATION IN GÉMEOS, A MÁRIO CLÁUDIO'S NOVEL}

\begin{abstract}
This article proposes a reading of Gémeos, a novel written by the Portuguese author Mário Cláudio, from the dialogue that the literary text establishes with some pictures of the Spanish painter Goya. We will see how, from the interaction between different forms of artistic production, the text allows that the readers question the limits and possibilities of the fictional language, explaining the processes of creation and creating, this way, an attentive reader, that need to get rid of a comfortable situation to become producer of knowledge.
\end{abstract}

KEYWORDS: Gémeos, by Mário Cláudio; Goya ; dialogue between arts; reader formation.

O romancista nem demonstra nem conta: recria um mundo

Octavio Paz

O escritor Mário Cláudio é um dos principais nomes da produção romanesca contemporânea de Portugal. De sua extensa obra, destacam-se as (muitas) biografias ficcionais, como é o caso da chamada Trilogia da mão, formada pelos romances Amadeu (1984), Guilhermina (1986) e Rosa (1988), respectivamente criações literárias da vida dos seguintes artistas: o pintor Amadeo de Sousa-Cardoso, a violoncelista Guilhermina Suggia e a artesã Rosa Ramalho. A esses livros somam-se outros, como As Batalhas do Caia, que apresenta, de forma ficcional, fases da vida de Eça de Queirós, e o romance Gémeos (2004), que consiste em objeto de análise deste breve artigo. Este livro dialoga com a vida e a obra do pintor espanhol Francisco José Goya e integra a Trilogia das constelaçoes, também composta por Ursamaior (2000) e Orion (2003).

Mais do que brindar seus leitores com aspectos da trajetória de vida de artistas muito ou pouco conhecidos do grande público, os romances escritos por Mário Cláudio

\footnotetext{
${ }^{1}$ Doutoranda do Programa de Pós-Graduação em Letras da Universidade Federal Fluminense (UFF/RJ) Estudos Comparados de Literatura.
} 
vão muito além das referências biográficas e/ou históricas. Construídos entre o documental e o imaginário, eles despertam fecundas reflexões sobre o frutífero diálogo que pode ser estabelecido entre linguagens distintas, o poder da criação e os limites da produção artística - produção esta que marca a vida dos personagens convocados por ele nos livros citados, já que são artistas reconhecidos em seu país e/ou mundialmente. Como afirma a pesquisadora Dalva Calvão,

da construção de biografias ficcionais - em que se colocam questões fundamentais sobre a narrativa contemporânea - o texto de Mário Cláudio caminha em direção a uma mais ampla reflexão, da qual fazem parte questões como o diálogo entre as artes, uma determinada valoração da obra de arte e a consciência da tarefa crítica do escritor (CALVÃ̃o, 2008, p. 11)

Ao propor um fecundo diálogo entre formas de produção artística - neste caso, entre literatura e pintura - e levantar questionamentos acerca dos limites e possibilidades da linguagem ficcional, o romance se afasta da concepção de autor-Deus para demandar um leitor atento e produtor de conhecimento. Como diz Barthes, "não existe por trás do texto ninguém ativo (o escritor) e diante dele ninguém passivo (o leitor); não há um sujeito e um objeto” (BARTHES, 2002, p. 23). Em Gémeos, esse leitor ativo vai se construindo ao longo da obra, mostrando que, como afirma Proust, "a leitura está no limiar da vida espiritual; ela pode nela nos introduzir, mas não a constitui” (PROUST, 1989, p. 32).

\section{Literatura e pintura: diálogo entre artes}

Gémeos parte da história do famoso pintor espanhol Francisco José de Goya (17441828), focando especialmente nos últimos momentos de sua já "avançada vida" (CLÁUDIO, 2004, p. 18). Foi nesse período que ele criou as suas famosas "Pinturas Negras", uma série de quatorze quadros que o artista "realizou a óleo diretamente sobre as paredes de duas salas da chamada Quinta del Sordo, próxima ao Rio Manzanares, propriedade que adquiriu em 1819 e que deixou a seu neto Mariano em 1823, antes de ir para a França"2. Aliás, em nenhum momento é citado na narrativa o nome Goya, pelo qual

\footnotetext{
${ }^{2}$ Enciclopédia online do Museu Nacional del Prado. http://www.museodelprado.es/enciclopedia/enciclopedia-on-line/voz/pinturas-negras-goya/ Acesso em 28 de janeiro de 2015.
} 
o pintor ficou famoso. Nela, é Dom Francisco quem merece o foco, distanciando-nos de toda concepção pré-estabelecida que podemos ter do artista espanhol.

O enredo se constrói a partir da chegada do protagonista a essa nova residência: "A Quinta fora comprada com o meu dinheiro, vinte e seis hectares de terreno" (CLÁUDIO, 2004, p. 19). Lá ele conviveu com Dona Leocádia, que ficou conhecida como sua amante, e Rosário, filha dela, ambas transformadas em personagens pela escrita do autor português. Em Gémeos acompanhamos, página a página, o avanço progressivo do envelhecimento do protagonista, que vai sentindo no corpo e na perda da própria virilidade o passar dos anos e a aproximação da morte. Sua idade avançada é em vários momentos anunciada, com a espera de Dona Leocádia pelo momento em que se tornaria, acredita ela, herdeira de sua riqueza, e pelo contraponto à juventude de Rosarito, por quem o artista tem uma profunda obsessão e, ao mesmo tempo, inveja da mocidade. Já no final do romance, ao imaginar o fim que ela teria tido após fugir para a França, o personagem deixa claro esse sentimento: "Eu sentir-me-ia inteira e magnificamente vingado. Também a ela haveria de alcançar a sombra da velhice, o esqueleto amarelento que habita um invólucro de pele esburacada [...] Recordar-se-ia do ancião surdo e mudo de que tanto havia troçado” (2004, p. 130).

$\mathrm{Na}$ Quinta del Sordo, o pintor espanhol tornou-se vítima de incontáveis pesadelos e assombrações. O texto literário acompanha este momento da vida e da sua produção artística, no qual destacam-se quadros sombrios, fantasmagóricos e de tonalidade pesada. No entanto, o tempo se expande a partir das lembranças do protagonista, por meio das quais são recuperadas suas obras anteriores, como o tempo em que foi retratista oficial da Corte Real e participou de concursos, como os da Academia de Belas Artes de Madri e de Parma, além da fama de se ter envolvido em diversas aventuras amorosas: "Revolvia o passado, e apenas desenterrava cuidados, concursos de que deveria sair vitorioso, retratos que se impunha concluir dentro do prazo, mulheres que se me entregavam" (CLÁUDIO, 2004, p. 38).

Em Gémeos, "as obras de Goya, recriadas pela palavra do narrador, atravessam todo o romance e o desejos e angústias que acompanham o processo criativo fazem-se evidentes ao longo do texto" (CALVÃO, 2008, p. 37, grifo meu). Ou seja: estabelece-se o diálogo do texto com a pintura de Goya, promovendo a "verbalização de textos reais ou fictícios compostos em sistemas não-verbais", o que Clauss Clüver define como ekphrasis (CLÜVER, 1997, p. 42). Segundo o pesquisador, toda ekhphrasis é uma reescrita mais ou 
menos fiel ao elemento de origem. Quando se trata do mundo literário, "a maioria delas tende a atingir autonomia em relação ao texto-fonte, o qual transformam de acordo com as necessidades do texto literário onde funcionam" (idem).

O romance de Mário Cláudio realiza tal reescrita criativa e interpretativa a partir das pinturas de Goya, imagens recriadas de acordo com o funcionamento interno do romance. São vários os momentos em que isso ocorre. Há, por exemplo, referências explícitas a famosos quadros do pintor espanhol, sempre convocados para estabelecer relação com algum personagem da obra ou para enfatizar algum momento da narrativa. Alguns deles são: "Os fuzilamentos de Maio", "Saturno devorando seus filhos" e "O cão semiafundado", obras cujas reelaborações literárias seguem, respectivamente:

E agora ouçam o que vos conto porque nunca mais o repetirei. Enquanto se enfiava Rosarito, apanhando as saias, pelos dentros do maciço e canas, e o coração me batia no peito como nem sequer me sucedera diante dos fuzilamentos de Maio [...] (CLÁUDIO, 2004, p. 36)

Decorreram duas semanas, prossegui nos empastes daquele Saturno que me assombrava os dias. Ampliava-se o velho, louco como nunca, por dentro de mim e para além do meu inferno. (p. 39) [...] O velho deus escancarava os olhos sanguinolentos, e toda monstruosidade do Planeta se quedava neles reflectida. E apertava entre os dedos o corpo hirto de Rosarito, pronto a esquartejá-la antes de a levar à boca [...] (p. 45)

Numa das paredes do corredor, e no silêncio abafado, luta Dom Beltrán, o cão, com o terrível pesadelo, porfiando por se libertar daquela duna imensa onde mais e mais se vai enterrando. [...] Volta Dom Francisco a respirar muito fundo. Movem-se as três parcas no painel de tintas lúgubres, trocam risos entre si, e avança a mais implacável, vogando na extrema ligeireza. Estremece numa gargalhada, corta certeiramente o débil fio de prata (p. 133)

No primeiro caso, o horror da guerra é recuperado como elemento de comparação com a dor do personagem que sente uma imensa atração pela jovem Rosarito e sabe ser impossível a correspondência do seu desejo. Já o famoso Saturno, deus sanguinolento que devora o próprio filho, é recuperado em analogia ao protagonista da obra, possibilitando, segundo a pesquisadora Loiana Pavlichenko, “a associação da imagem dele à do pintor, de maneira que Dom Francisco possivelmente se vê como ele, capaz de matar a sua cria [Rosário], condenando-a ao cárcere, roubando-lhe a liberdade e, por conseguinte, o frescor e a vivacidade da juventude” (PAVLICHENKO, 2008, p. 50). Já uma das referências ao “Cão semi-afundado", esta já no final do livro, reproduz o momento de aproximação da 
morte do pintor, quando seu corpo estaria sendo afundado pelo peso do tempo e de seus próprios pesadelos. Este quadro aparece na capa do livro publicado pela Editora Dom Quixote (2004) e, no romance, o cão nomeado Dom Beltrán é eleito companheiro fiel do protagonista. Nesta cena final também é convocado o quadro "Las parcas", uma das "Pinturas Negras" encontradas nos muros da Quinta del Sordo.

Se o leitor atento e aplicado não tiver um profundo conhecimento das obras do pintor, pode guiar-se pelas pistas fornecidas pelo texto e se ir enriquecendo a partir das referências contidas na obra. É o que exemplificam os seguintes trechos:

Para a outra parede iria alastrar por isso uma Judite implacável, saída dos expectantes muros da sua cidade de Betúlia. [...] E assim a acolhia Holofernes em sua tenda, e pretendia na embriaguez em que se afogava arrastá-la para o leito protegido por um mosquiteiro bordado a ouro e a esmeraldas (CLÁUDIO, 2004, p. 45 - "Judith e Holofernes")

Falou-me de um manicómio que eu conhecera muito bem, e dos doudos que pelos átrios dele vagueavam desnudos, os quais andara eu outrora a pintar (p. 54 - "O Manicómio")

Com Simón partilhava eu assim longínquos segredos de horror que ninguém compreenderia. Eram muitíssimos mais do que esses que reproduzira nas oitenta e cinco gravuras onde a guerra range e explode, e que constituem código ao alcance de toda a gente. (p. $64-$ série "Os desastres da guerra")

$\mathrm{Na}$ parede do comedor, situada à direita da janela, aproveitando talvez a ventania que por aí entrava, e que haveria de enfunar as vestes dos seus figurantes, reproduziu Dom Francisco o grande demônio Asmodeu, guloso de virgens como nenhum outro. E surgiu o malvado como um grosseirão, pesado de concupiscência, arrebatando a sua donzela pelos ares. (p. 78 - "Asmodeu")

"Alçou-se depois calmamente, e foi observar o quadrinho que eu suspendera na parede, e que representava um grupo de canibais que preparavam suas vítimas" (p. 123 - "Canibais preparando sua vítima")

Além destas, há muitas outras passagens que fazem referência, explícita ou não, a uma pintura de Goya. Mas o diálogo interartes não se estabelece apenas nestes momentos. Há uma recuperação, ao longo do romance, do tom sombrio que marca a pintura da fase final do artista espanhol, exatamente a do período em que ele esteve na Quinta del Sordo, 
momento retratado na obra de Mário Cláudio. É comum o artista-personagem ser vítima de terríveis sonhos, repletos de "monstros grosseiríssimos que os habitam" (CLÁUDIO, 2004, p. 98) como o que se segue:

As noutes abismavam-se em pesadelos de que eu não possuía a chave, e atravessava-os uma menininha com as faces tingidas de carmim, arregaçado a camisa até ao alto das coxas [...] Sentava-me depois na cama, e um mareio atirava com o quarto a navegar num oceano tempestuoso, e rasgava-me um apito feroz o que me sobrava dos ouvidos. Doía-me que dormisse tranquilamente na sua alcova Rosarito, autora de tantos padecimentos. (p. 37)

A narrativa tem como base a junção de elementos opostos - sombra-luz; espessura e transparência; juventude e morte - que são os mesmos presentes na obra do espanhol, como ele mesmo, transformado em personagem, revela: "punha-me eu a fazer deslizar aquele gordo crayon numa laje de pedra, sombra aqui, claridade além, espessura e transparência, juventude a romper, cercania da morte" (CLÁUDIO, 2004, p. 25, grifos meus).

$\mathrm{Na}$ famosa gravura "O sonho da razão produz monstros" ${ }^{3}$ é possível enxergar o tom fantasmagórico que assombra o pintor ao longo do romance de Mário Cláudio. O elemento sombrio presente na pintura e na vida de Dom Francisco se projeta nos ataques de pânico que o pesquisador-biógrafo passará a sentir após os estudos sobre o artista espanhol, "reduzindo-lhe a existência a um itinerário permanentemente perseguido, senão ameaçado, pela máscara do desastre e da morte" (CLÁUDIO, 2004, p. 48), transformando biógrafo e biografado em duplos/gêmeos no romance:

Do plano térreo que correspondia ao da entrada principal [do Museu] até ao andar onde se poderiam alcançar as obras do seu pintor não mediaria mais do que uma quarentena de degraus, capazes de todavia lhe alterar por completo o rumo da existência, e muito especialmente o modo de a encarar. [...] Era no pavor infrene que se debatia como num mar imenso, destituído de tábua de salvação, entregue ao furor que não lograva identificar senão como a catástrofe final do Universo criado. [...] Acabava de sofrer o primeiro ataque de pânico, de uma sinistra procissão de centenas de outros que ao longo dos anos se repetiriam (p. 42)

Não é apenas com o pesquisador que Dom Francisco estabelece um jogo especular. Outros personagens se projetam como duplos do protagonista, o que poderia servir como uma explicação possível para a escolha do título da obra - o qual, aliás, não revela, a

\footnotetext{
${ }^{3}$ Anexo 1 (p. 12).
} 
princípio, relação direta com o enredo que nos é apresentado. A constelação de Gêmeos é citada duas vezes ao longo do livro a partir da narração de Dom Francisco, respectivamente em cenas que convocam os dois polos de força sobre os quais se tece o romance: a morte - pela lembrança de um cadáver de guerra: "Jamais confessei, nem a tinta negra, o pavor que nesse instante se apoderou de mim, ao acercar-me do morto, e ao debruçar-me para o rosto de leite. Estampavam-se-lhe nos olhos escancarados como charcos enormes, as sete estrelas de Gémeos" (CLÁUDIO, 2004, p. 65); e a vida - pela referência à menstruação de Rosarito: "E só então distingui a almofada sobre que se sentara ela, manchada pelas espessas gotas de sangue que resumiam o trânsito a mulher, distribuídas de forma a compor a figura da constelação e Gémeos” (p. 89).

Loiana Pavlichenko ressalta que o título da obra também pode ser entendido a partir da constelação de personagens que circulam pela trama e interagem com Dom Francisco:

Considerando-se, portanto, que a constelação de Gémeos é composta
por sete estrelas - Castor, Pólux, Mebsula, Tejat, Pólux, Mekbuda Wasat
e Alhena - e que comentamos a relação de atração e repulsão que se
efetua entre Dom Francisco e a menina Rosarito, procuramos no texto
de Mário Cláudio as outras cinco, ou seja, os outros polarizadores da
subjetividade de Dom Francisco que, como veremos, se reduplica nas
seguintes personagens: Dom Beltrán; o cachorro; o Dr. Arrieta, o
médico; Simon, o jardineiro; Dona Leocádia, a amante; e o pesquisador.
(PAVLICHENKO, 2008, p. 45)

Feito para "confundir as ideias, não para discipliná-las" (ECO, 1985, p. 9), a escolha do nome do romance, em nenhum momento explicitada, é mais um elemento que convoca o leitor a participar da narrativa e a construir seu próprio conhecimento, o que começa desde o primeiro contato com a obra. Assim como a dúvida sobre o título, outras dúvidas estão por vir, e cabe ao leitor ativo e aplicado construir sua formação a partir das reflexões postas e sugeridas pelo texto. Ler Gémeos é concordar com Proust quando diz que ao invés de Conclusões um belo livro nos oferece Incitações, pois "sentimos muito bem que nossa sabedoria começa onde a do autor termina, e gostaríamos que ele nos desse respostas, quando tudo o que ele pode fazer é dar-nos desejos" (1989, p. 30-31).

Ao convocar, direta e indiretamente, obras do pintor Goya e, a partir delas, elaborar seu texto ficcional, o autor levanta questionamentos acerca dos limites entre ficção e realidade, referência e imaginação, propondo em seu livro-pintura a recusa de 
representações figurativas e preferindo, assim, uma arte mais abstrata - caminho, inclusive, percorrido pelo artista transformado em protagonista da obra. Realiza-se, assim, um jogo entre "sonho" e "razão" que tira o leitor acomodado de seu lugar.

\section{O jogo criativo em Gémeos: reflexões sobre a escrita}

Ler Gémeos não é tarefa fácil. Pelo contrário: é mais um exemplo da opção de Mário Cláudio "por um texto que se interroga e que convoca de forma exigente a atuação do leitor [...]" (CALVÃO, 2008, p. 27). Ele requer um regime aplicado de leitura que não deixa passar nada, o único possível em um texto de fruição que rompe com uma prática confortável. A leitura "pesa-se, cola-se ao texto, lê, se se pode assim dizer, com aplicação e arrebatamento, apreende em cada ponto do texto o assíndeto que corta as linguagens; [...] não é a extensão lógica que a cativa, o desfolhamento das verdades, mas o folheado da significância" (BARTHES, 2002, p. 18). Folhear as páginas do romance procurando verdades é em vão; o que há são sugestões, recriações, reflexões. É um tipo de texto perverso pelo fato de "estar fora de qualquer finalidade imaginável" e muitas vezes é preciso insistir, pois “a fruição não obriga ao prazer; pode mesmo aparentemente aborrecer" (ibidem, p. 62).

Como já afirmado, a referência às pinturas do espanhol são explícitas algumas vezes, mas nem sempre. Além do mergulho no universo produtivo de Goya, o leitor é guiado por três vozes narrativas, que se revezam ao compor essa biografia, ao mesmo tempo em que subvertem o gênero. O jogo ficcional nos é revelado desde a primeira página, sugerindo ser inútil a tentação de procurarmos, nas linhas que se seguem, registros da "vida" do espanhol, tal como foi. Somos, de início, apresentados ao pesquisador que está em um Museu empreendendo uma série de estudos sobre o artista que tanto o fascina. A criação, ou seja, a elaboração literária a partir do registro de fatos é, portanto, revelada logo no início do romance. Dizem as primeiras linhas:

Estava ele pois naquele Verão encalhado na cidade peninsular, a fim de empreender, munido de um problemático subsídio de estudos, uma certa indagação sobre a fase última do pintor. Desde há anos que um arraigado enamoramento, alimentado pelas renascenças a que as várias vanguardas sujeitavam o trabalho dos anos terminais do artista, lhe fora tornando fatal a decisão de uma permanência. (CLÁUDIO, 2004, p. 11-12) 
Após extensa investigação, que o levaria a sofrer crises de pânico e tornar-se vítima de pesadelos e alucinações, o pesquisador enfim "começaria a escrever as primeiras páginas dos últimos tempos do pintor" (CLÁUDIO, 2004, p. 116). A composição dessa biografia corresponde a vários capítulos de Gémeos, que, como já afirmado, apresentarão diferentes vozes narrativas. $\mathrm{O}$ uso da primeira pessoa em alguns momentos transforma o próprio pintor espanhol em guia do enredo, sugerindo uma fictícia autobiografia escrita pelo pesquisador, onde são convocadas figuras históricas que, de fato, conviveram com o artista - como D. Leocádia e Rosarito. O trecho a seguir, que inicia o segundo capítulo, exemplifica tal afirmação:

Chegámos com as três azémolas e as duas carripanas que transportavam o resto dos trates. Eram cinco e quarenta, e a tarde refrescara um pouco. (...) Fiquei depois a contemplar o panorama da Cidade, reservando para outra ocasião o ingresso na casa, momento que haveria de ser para mim, mas só para mim, de singular solenidade. Pretendia observar entretanto o rio nervoso e faminto que me separava da Capital (...). Avancei para a casa, reparando em Dona Leocádia afadigadíssima (p. 17, grifos meus).

Dom Francisco explicita em diversos momentos sua condição de escritor da própria história, interagindo, por exemplo, com seus leitores: "Que significa de facto a morada a que nos habituamos, meus senhores, senão o ataúde que nos há-de guardar?” (CLÁUDIO, 2004, p. 18); "E agora ouçam o que vos conto porque nunca mais o repetirei” (p. 36). Em certos momentos também é possível perceber, a partir de pistas sutis, a incerteza que acompanha o que o pintor-autor está a narrar, como por exemplo o uso dos verbos "adivinhar" e "suspeitar" e a opção preferencial pelo futuro do pretérito: "E adivinhei, isto embora nada pudesse ouvir, nefando surdo que já era, os pés descalços da monstra, pata aqui pata acolá" (p. 86); "Sempre em segredinhos, atirando-me miradas de revés, andariam organizando, suspeitava eu, os magnos festejos da minha morte” (p. 106); "eu sabia exactamente o teor da carta que Dona Leocadia ia redigindo, e que haveria de ser o seguinte" (p. 101, grifos meus). Ele também chega a reconhecer os limites da letra frente às dores do mundo - e, por consequência, da arte em geral:

O homem limpou o ranho à manga da camisa, tossiu secamente, e comprometeu-se a dar cumprimento a um plano que apenas os como ele, sofredores do que nenhuma pena de escrita conseguiria descrever, ascenderam a contemplar. [...] E eu registro a história desse desventurado, sobre 
o qual desastres e mais desastres não cessariam de se abater. (CLÁUDIO, 2004, p. 62-63, grifo meu)

No capítulo seguinte uma terceira vOz toma a cena e narra, distante dos acontecimentos, momentos dessa mesma fase da vida de Dom Francisco. Tudo indica que é a biografia que o pesquisador está escrevendo, ainda em dúvida se deve usar a primeira ou a terceira pessoa:

Ele percorria as quadras da nova casa, e o frio da serra mordia-lhe o ossos emperrados. [...] E remexia na ideia o caldeirão das substâncias que esconjurassem os espíritos maus, óleos pastosos sobre os estuques, amplos volumes entenebrados, uma nuvem de sinistros viajantes (CLÁUDIO, 2004, p. 29, grifos meus).

Ao lançar mão de duas vozes narrativas distintas para simular a escrita da autobiografia/biografia de Goya a partir das averiguações do biógrafo-personagem, o romance revelaria a "indecisão do pesquisador quanto à forma que desejaria para o seu trabalho, bem como as estratégias de escrita possíveis para dar conta da vida e da obra do pintor" (PAVLICHENKO, 2008, p. 22), sugerindo que a busca por um "relato fiel" é infrutífera, inacabável e, portanto, não há possibilidade de uma solução definitiva. Como lembra a pesquisadora Leila Perrone-Moisés, o discurso nunca será capaz de dar conta do real; pode, apenas, tangenciá-lo, recriá-lo. “A linguagem não pode substituir o mundo, nem ao menos representá-lo fielmente. Pode apenas evocá-lo, aludir a ele através de um pacto que implica a perda do real concreto. [...] Narrar uma história, mesmo que ela tenha ocorrido, é reinventá-la” (PERRONE-MOISÉS, 1990, p. 105).

Reflexão semelhante estabelece o próprio personagem, ao perceber, após a degeneração do corpo com o passar dos anos, como a realidade também não é precisa, e sua representação é sempre incompleta:

Durante os meus passeios, solitários depois que Rosarito me traíra, ia-me apercebendo de como era ondulante e esfumada a paisagem, raramente se precisando em suas linhas. E a tristeza descia-me à alma, amargurada pelo que em sabia significar aquela despedida dos contornos e das cores. Para onde fora a concisão de antigamente, os volumes que, uma vez entrevistos, logo se dispunham na tela projectada, as iniludíveis tonalidades do verde e do azul e do amarelo, enquadradas pela chapada do vermelho, através das quais se me arrumava o Mundo naquilo que ia pintando? (CLÁUDIO, 2004, p. 105) 
Frente a essa constatação dos limites da linguagem artística, em vez de se renunciar à volta ao passado, muitos escritores optam por revisitá-lo de maneira não-inocente. Segundo Umberto Eco, eles lançam mão de "ironia, jogo metalinguístico, enunciação elevada ao quadrado" (1985, p. 57) para expor o caráter ficcional de qualquer abordagem histórica, inclusive da própria biografia, que é sempre uma construção.

\section{Conclusão}

Recuperando a citação de Octavio Paz, sem demonstrar nem contar, Mário Cláudio recria um mundo próprio da ficção. Esse artigo teve como objetivo mostrar que Gémeos parte da vida e obra de um artista espanhol consagrado não como uma tentativa de apreensão de um passado, mas sim para a "elaboração de um processo auto-reflexivo e questionador” (CALVÃO, 2008, p. 27). Já que, como destacou Umberto Eco, o romance é "uma máquina para gerar interpretações" (1985, p. 8), a partir da convocação das pinturas do artista e da exposição do jogo ficcional, os leitores são postos em movimento para assumir uma postura criadora e questionadora quanto ao poder e limites da criação estética, além de possibilitar um mergulho nas obras de Goya.

Já que "qualquer linguagem deforma as coisas, e a linguagem plena do escritor, para dar verdade às coisas, assume decididamente seu estatuto de artifício e ilusão" (PERRONE-MOISÉS, p. 106) resta-nos entrar no jogo da fruição e produzir conhecimento a partir do texto, compartilhando do gozo festivo que aproxima escrita e imagem, literatura e pintura, passado e presente, morte e vida, história e ficção.

\section{Referências bibliográficas}

BARTHES, Roland. O prazer do texto. Trad. J. Guinsburg. São Paulo: Perspectiva, 2002. CALVÃO, Dalva. Narrativa biográfica e outras artes: reflexões sobre escrita literária e criação estética na Trilogia da Mão, de Mário Cláudio. Niterói: EdUFF, 2008.

CLÁUDIO, Mário. Gémeos. Lisboa: Dom Quixote, 2004.

CLÜVER, Clauss. "Estudos interartes: conceitos, termos, objetivos". In: Literatura e

Sociedade - Revista de teoria literária e literatura comparada. São Paulo, USP, 1997, n. 2, p. $37-55$.

ECO, Umberto. Pós-escrito a O nome da rosa. Trad. Letizia Zini Antunes e Álvaro Lorencini. Rio de Janeiro: Nova Fronteira, 1985. 
PAZ, Octavio. "Ambiguidade do romance”. Trad. Sebastião Uchoa Leite. In PAZ,

Octavio. Signos em rotação. São Paulo: Perspectiva, 1976, p. 63-74.

PERRONE-MOISÉS, Leyla. “A criação do texto literário”. In PERRONE-MOISÉS,

Leyla. Flores da Escrivaninha. Ensaios. São Paulo: Companhia das Letras, 1990, p. 100-110.

PROUST, Marcel. Sobre a leitura. Trad. Carlos Vogt. Campinas: Pontes, 1989.

\section{Referências online}

Enciclopédia do Museo Nacional del Prado. Disponível em http://www.museodelprado.es/enciclopedia/enciclopedia-on-line/voz/pinturas-negrasgoya/ Acesso em 28 de janeiro de 2015.

PAVLICHENKO, Loiana. Entre palavra e imagem: Gémeos, de Mário Cláudio. Dissertação de mestrado em Literatura Portuguesa. UFF: 2008. Disponível em http://www.bdtd.ndc.uff.br/tde arquivos/23/TDE-2009-07-29T120958Z-

2153/Publico/Loiana\%20Leal\%20Pavlichenko-Dissert-Letras.pdf Acesso em 25 de janeiro de 2015 .

\section{Anexo 1}




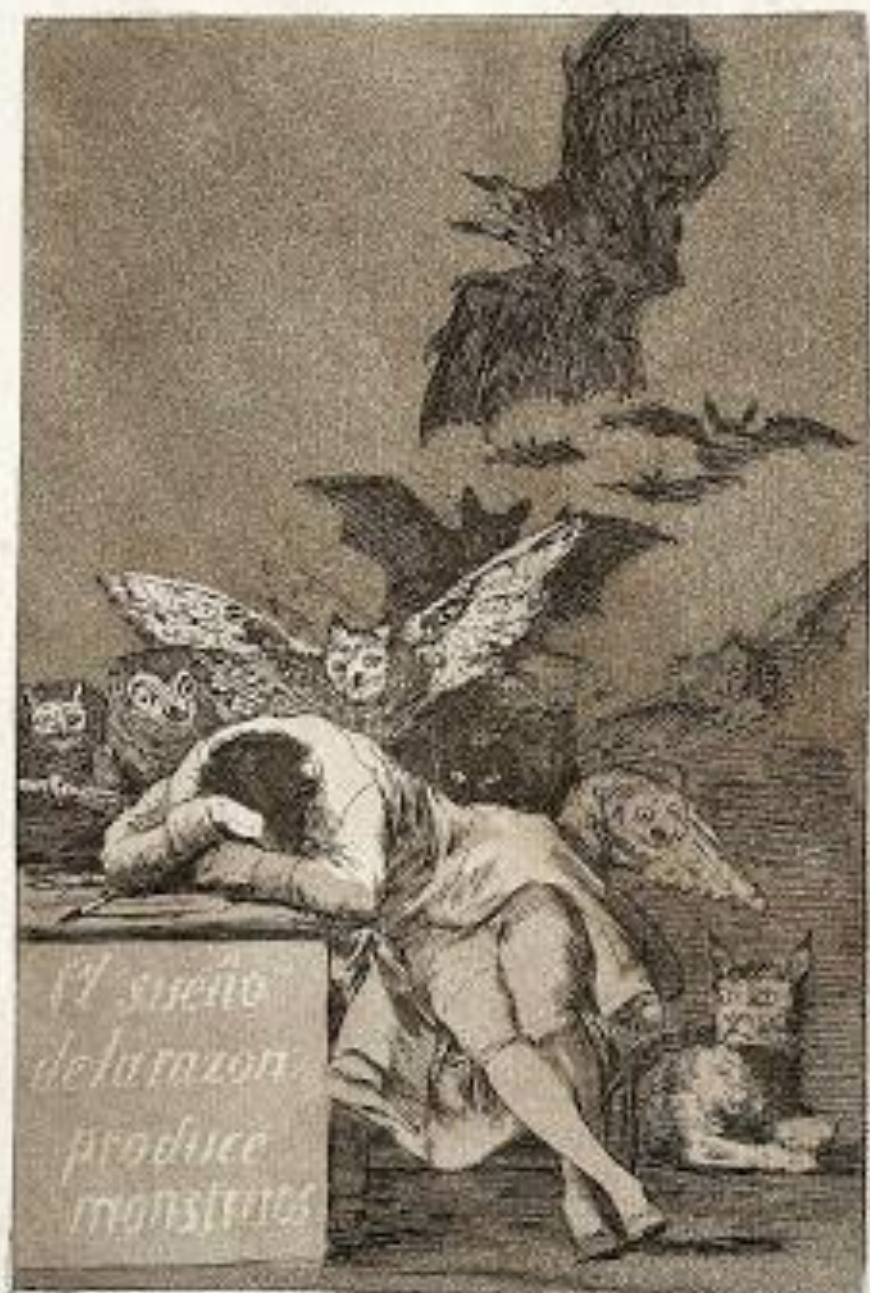

